\title{
Short communication: Stall occupancy behavior of Nili Ravi buffaloes (Bubalus bubalis) when first introduced to freestall housing
}

\author{
S. H. Magsi, ${ }^{*}$ M. N. Haque, $†$ N. Ahmad, ${ }^{*}$ and M. Q. Shahid ${ }^{* 1}$ \\ *Department of Livestock Production, and \\ †Department of Animal Nutrition, University of Veterinary and Animal Sciences, Lahore 54000, Pakistan
}

\begin{abstract}
The aim of the present study was to assess stall occupancy of Nili Ravi buffaloes when first introduced to freestall housing. Thirty Nili Ravi buffaloes of different parity, weight, and pregnancy status were enrolled from the dairy farm of the University of Veterinary and Animal Sciences, Lahore, Pakistan. All of the enrolled animals had no previous experience with freestalls. The selected buffaloes were introduced to the freestall shed. During an adaptation period of $7 \mathrm{~d}$, all buffaloes had 24 $\mathrm{h}$ of free access to lie down in 1 of 3 areas: (1) freestalls, (2) alleys, and (3) an outside open area. After the adaptation period, all buffaloes were housed indoors during nighttime (restricted period) to ensure that only freestalls or alleys were available as lying areas. An observer monitored animals at $0100 \mathrm{~h}$ and recorded the number of animals lying in freestalls, in alleys, and in the outside open area. The results indicated that during the adaptation period, herd-level freestall occupancy in buffaloes remained below 10\%. During the restricted period, herd-level stall occupancy was $0,13,50$, and $90 \%$ on $\mathrm{d} 1,2,5$, and 17 , respectively. Buffaloes with parity $\geq 3$ took fewer days $(6.6 \pm 1.0$; mean \pm standard error of the mean) to occupy stalls than buffaloes with parity 2,1 , and heifers $(13.2 \pm 1.5,16.7 \pm 2.1$, and $13.5 \pm 2.1 \mathrm{~d}$, respectively). Body weight and pregnancy status of buffaloes did not have any effect on stall occupancy. Buffaloes showed adjacent stall occupancy, filling opposite stalls first. The results indicated that older buffaloes occupied freestalls earlier than younger buffaloes. Our findings would help better manage buffaloes in freestall housing.
\end{abstract}

Key words: buffalo, freestall, occupancy, behavior

Received July 31, 2017.

Accepted October 24, 2017.

${ }^{1}$ Corresponding author: qamar.shahid@uvas.edu.pk

\section{Short Communication}

Water buffalo (Bubalus bubalis) are the second (14\%) ranked milk-producing animals in the world after cattle (83\%). In countries such as India and Pakistan, buffalo milk contributes more than $50 \%$ of total milk production (FAOSTAT, 2017). Buffaloes are kept tethered on a sloped floor with bricks and concrete as a resting surface. The lying surface remains wet and dirty with the animal urine and feces, thereby increasing the risk of udder health problems, especially in herds of periurban areas. Under these housing conditions buffaloes are unable to express their natural behavior and reach their full productive potential.

Freestall housing is a good alternative that provides a dry, clean, and comfortable resting surface for animals (von Keyserlingk et al., 2011). Freestall design features such as stall dividers (Tucker et al., 2004), brisket boards (Tucker et al., 2006), and neck rails (Bernardi et al., 2009) help maintain stall cleanliness by reducing the risk of cows soiling the stall. They also provide a better working environment (Valde et al., 1997) that allows reduced labor (Abade et al., 2015) and efficient time usage (Fregonesi et al., 2009a). Animals exhibit more natural behavior in freestall housing than in tied systems. However, the hardware used in stalls, such as stall partitions, neck rails, and brisket boards (Fregonesi et al., 2009b), might hinder animals from using freestalls, especially animals that are newly introduced to a freestall facility. Previous studies on cattle indicated that heifers were more reluctant to use freestalls than cows when first introduced to a freestall barn (Kjæstad and Simensen, 2001). Higher stall refusal increases the chances of lying down in alleys, thus making animals more prone to udder problems (Abebe et al., 2016). Limited data are available about buffalo behavior in freestall housing.

Our objectives were to assess stall occupancy and lying patterns of Nili Ravi buffaloes when first introduced to freestall housing. We also evaluated the effect of parity, pregnancy status, and BW on stall usage in buffaloes. 
This study was conducted at the Dairy Animals Training and Research Center, University of Veterinary and Animal Sciences, Lahore, Ravi Campus, Pakistan. The observations were recorded in October 2015. The average temperature of the shed during day and night for the month of October was (mean \pm SD) $28.0 \pm$ $1.7^{\circ} \mathrm{C}$ and $20.3 \pm 3.2^{\circ} \mathrm{C}$, respectively, with range of 26 to $32^{\circ} \mathrm{C}$ and 16 to $26^{\circ} \mathrm{C}$, respectively.

Thirty nonlactating Nili Ravi buffaloes were selected from the dairy center. The imprint length and width of these buffaloes were (mean \pm SD) $171.5 \pm 9.6 \mathrm{~cm}$ and $95.3 \pm 5.3 \mathrm{~cm}$, respectively, with a range of 156 to $188 \mathrm{~cm}$ and 81 to $107 \mathrm{~cm}$, respectively. The buffaloes had no previous experience with freestall housing and were raised in a loose housing system with a concrete floor for the covered area and a dirt floor for the outside open area. All buffaloes were ear tagged and free from lameness (locomotion score $=1$ ). Lameness was assessed using a 5-point locomotion scoring system (on a scale of 1 to 5) developed for dairy cattle by Zinpro Corporation (Eden Prairie, MN).

The selected buffaloes were introduced to the freestall shed. For the initial $7 \mathrm{~d}$ (adaptation period), buffaloes had 24-h free access to lie down in 1 of 3 areas: (1) freestalls, (2) alleys, and (3) an outside open area. After the adaptation period, buffaloes were restricted under the shed during nighttime (restricted period) to force them to choose lying either in freestalls or in alleys. The restricted period lasted for $30 \mathrm{~d}$. During the restricted period, buffaloes had access to an open area during the daytime.

The freestall shed used for this study was naturally ventilated. It was $48 \mathrm{~m}$ long and $13 \mathrm{~m}$ wide, with 56 freestalls in 2 rows facing each other $(28$ stalls in each row). Freestall length, width, and neck rail position were 250, 117, and $178 \mathrm{~cm}$, respectively. Freestalls were filled above the curb surface with washed river sand. The alley floor of the shed was made up of concrete with parallel corrugations. The attached open area was $48 \mathrm{~m}$ long and $13 \mathrm{~m}$ wide and was located toward the north side of the shed with dirt (mixture of soil and sand) as a bedding material. Freestall stocking density (number of animals/number of freestalls) was $55 \%$. The outside open area provided $20.8 \mathrm{~m}^{2}$ of space per animal. The resting surface of the stalls was softer than the outside open area, as subjectively assessed by knee drop test. Freestalls were kept dry throughout the study period by pulverizing the bedding surface and removing wet, soiled sand. Manure from alleys was removed daily through scraping and washing. Manure from the outside open area was collected daily, and no plowing was done to dry or soften the resting surface. Sunlight and air were the main sources used to dry the outside open area. Buffaloes were given green fodder ad libitum twice daily at 1000 and $1900 \mathrm{~h}$. Water troughs were present under the shed and in the open area for free access to fresh water.

During the adaptation and restricted periods, an observer monitored animals approximately $1 \mathrm{~h}$ after every feeding and then during the night at $0100 \mathrm{~h}$. The average monitoring span was about $2 \mathrm{~h}$. These time intervals were selected to observe maximum lying behavior of animals because (1) on fresh feed delivery the latency to lie down in cattle is about $1 \mathrm{~h}$ (DeVries and von Keyserlingk, 2005) and (2) buffaloes showed the highest resting behavior during the night around 0300 and $2300 \mathrm{~h}$ (Odyuo et al., 1995). The observer recorded the number of animals lying in freestalls, in alleys, and in the outside open area. The individual buffalo was considered as an observational unit. For night recordings, observers used a torch to read the tags and count the animals.

Herd-level stall occupancy was expressed as a percentage and calculated as the number of animals lying in freestalls divided by the total number of animals in the shed. Animal-level stall occupancy was considered to be an event and was measured in days. The occupancy event was recorded when the animal used the freestall for 3 consecutive days. Freestall occupancy pattern was assessed as a preference to occupy (1) either alternative stalls or adjacent stalls, (2) stalls on the feed bunk side or open area side, and (3) stalls located near the entrance side or distant end of the shed. The effect of parity, BW, and pregnancy status on animal-level stall occupancy was evaluated. Parity was categorized into 4 groups: (1) heifers, (2) parity 1, (3) parity 2, and (4) parity $\geq 3$. Body weight was categorized into 4 groups: (1) $<460 \mathrm{~kg}$, (2) 461 to $520 \mathrm{~kg}$, (3) 520 to $560 \mathrm{~kg}$, (4) and $>560 \mathrm{~kg}$. Pregnancy status was categorized into 4 groups: (1) nonpregnant, (2) 1 to 3 mo pregnant, (3) 4 to 6 mo pregnant, and (4) 7 to 9 mo pregnant. Freestall occupancy during daytime remained below $20 \%$ (Figure 1 ). Therefore, only observations from night recordings were used for stall occupancy and its association with parity, BW, and pregnancy status.

Data were analyzed using SAS (university edition; SAS Institute Inc., Cary, NC). Herd-level freestall occupancy was descriptively presented in Figure 1. Effect of parity, BW, and pregnancy status on animal-level stall occupancy was determined by ANOVA using the GLM procedure of SAS. The bar and probability graphs were prepared using the ggplot2 (Wickham, 2009) and survminer (Kassambara and Kosinski, 2016) packages of R (R Core Team, 2016), respectively.

When buffaloes had free choice to lie down in freestalls, in alleys, and in the outside open area, only 
$10 \%$ of the buffaloes used freestalls, whereas $90 \%$ of the buffaloes used the outside open area. However, no buffalo lay down in alleys during the adaptation period (data not presented). The studies on freestall usage of buffaloes are limited; however, published data on cattle showed that when cows were given a choice between freestalls and open lying areas, they spent more time lying in an open area (Fregonesi et al., 2009b). Similarly, Fregonesi and Leaver (2002) reported that lactating cows preferred a straw yard rather than a cubicle system. The preference for lying in the open area could be attributable to the smaller lying space of the freestalls compared with the open area (Færevik et al., 2008; Fregonesi et al., 2009b) and hindrances associated with freestall hardware (Fregonesi et al., 2009b). However some studies showed that the nature of the lying surface is more important than the spatial constraints in cattle when making a decision about where to lie down (Tucker et al., 2005). Cows had a strong preference for lying on softer (Tucker et al., 2003) and more even (Drissler et al., 2005) stall surfaces.

Herd-level freestall occupancy of buffaloes during the restricted period is presented in Figure 1. When buffaloes were restricted under the shed during the night and were forced to lie down either in freestalls or in alleys, they started to use freestalls on $\mathrm{d} 2$. The percentage of buffaloes lying in freestalls increased from $13 \%$ on d 2 to $50 \%$ on d 5 and $70 \%$ on d 16 (Figure 1). Maximum freestall occupancy (90\%) was observed on d 17 and was maintained at maximum level $(\geq 90 \%)$ from d 22 on (Figure 1). Our findings are in agreement with studies conducted in cattle. von Keyserlingk et al. (2011) reported that the lying time of heifers in alleys was very short on the first day of introduction to freestalls, and it decreased on following days. Similarly, Kjæstad and Myren (2001) described that freestall refusal was highest during the first few days when cows were first introduced to a freestall shed. Buffaloes took more days to reach maximum stall occupancy in our study. These buffaloes were raised in a loose housing system with access to a concrete floor. It could be possible that longterm previous exposure to a concrete floor might have contributed to latency in freestall occupancy. However, the gradual increase in freestall occupancy in buffaloes implied that they did adapt to the restrictive freestall hardware.

Buffaloes showed adjacent stall occupancy, filling opposite stalls first. Buffaloes first occupied stalls that were located at the distant end of the shed. Buffaloes lying in alleys consistently lay down toward the outside

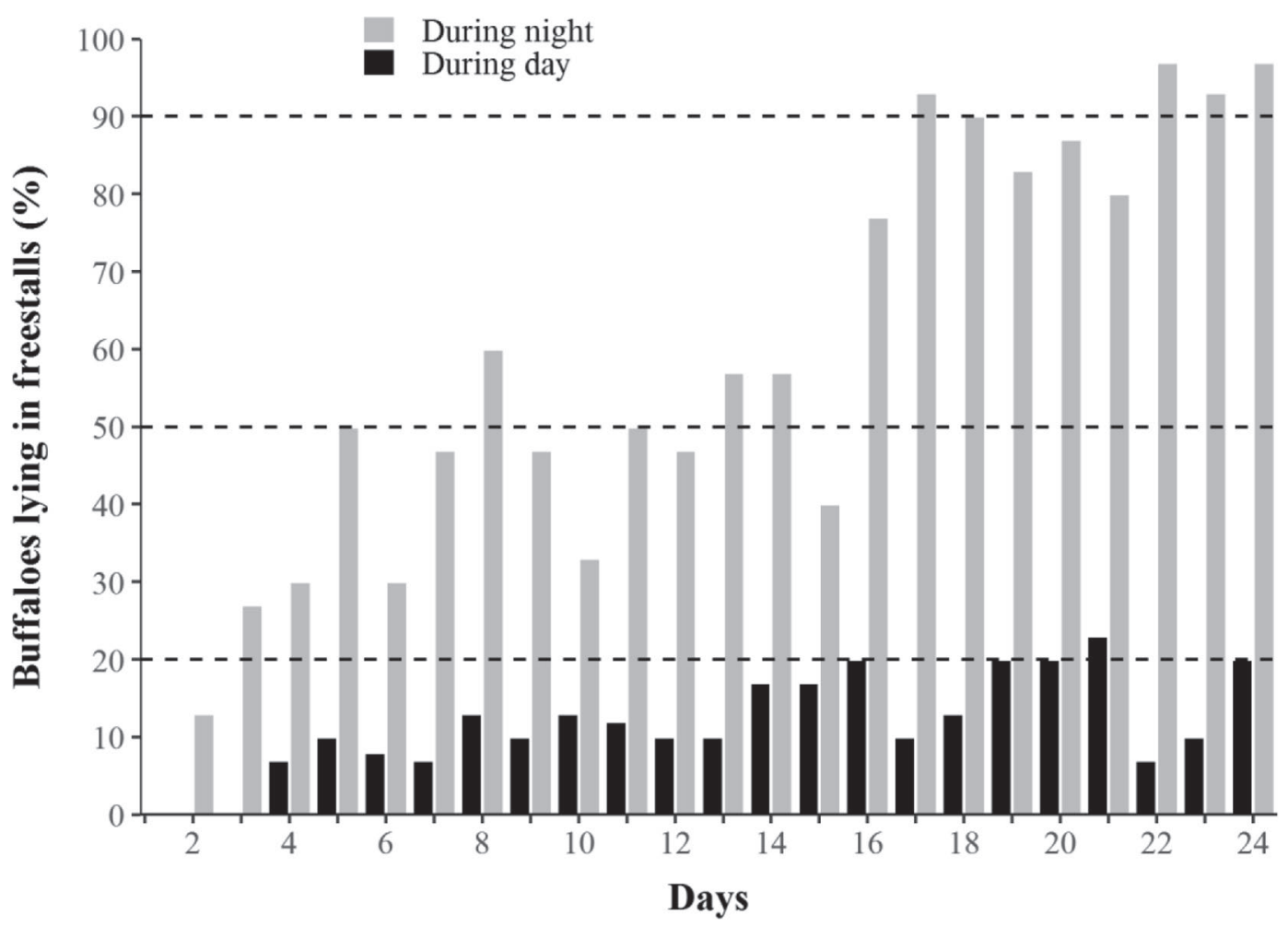

Figure 1. Buffaloes lying in freestalls (\% of total animals) during nighttime (when forced to choose lying in freestalls or in alleys; gray bars) and during daytime (when they had access to the outside open area; black bars) of the restricted period. 
open area near the occupied stalls. Also, buffaloes lying in the outside open area preferred to lie down in a grouped formation at the distant end of the open area. Contrary to buffaloes, cattle exhibit alternative stall occupancy and tend to occupy the resting area evenly. Previous studies indicated that in buffalo, an outstretched lying posture was more common than sternal recumbency with bent legs (Napolitano et al., 2004). We did not record lying posture of buffaloes in our study, so we were not certain whether lying posture determined the lying pattern of buffaloes. However, lying down in close proximity in stalls, alleys, and the outside open area implied that buffaloes had strong herding behavior. This behavior could be of critical importance when designing freestalls with an odd number of rows. To our knowledge, the current study is the first to report such behavior of buffaloes.

The effect of parity, BW, and pregnancy status on animal-level freestall occupancy in buffaloes is presented in Table 1. Parity significantly affected stall occupancy in buffaloes $(P<0.0001$; Table 1$)$. The average days taken (mean \pm SEM) to start occupying freestalls for buffaloes with parity $\geq 3,2$, or 1 and heifers were $6.6 \pm 1.0,13.2 \pm 1.5,16.8 \pm 2.1$, and $13.5 \pm$ $2.1 \mathrm{~d}$, respectively (Table 1 ). Buffaloes with parity $\geq 3$ started to lie down in freestalls about $6 \mathrm{~d}$ earlier than those with parity 2,1 , and heifers. Survival analysis revealed that buffaloes with parity $\geq 3$ started to occupy freestalls at d 3 and reached $100 \%$ occupancy at d 12, whereas buffaloes with parity 2 or 1 and heifers started to fill freestalls at d 4, 16, and 8 and reached $100 \%$ stall occupancy at d 20,17, and 16, respectively (Figure $2)$. Our results are in accordance with what has been reported earlier in cattle. Kjæstad and Simensen (2001) found that when cows were first introduced to freestall housing, $29 \%$ of the pregnant heifers were resistant to resting in cubicles, whereas only $3 \%$ of older cows were resistant to using cubicles. Likewise, Tucker et al. (2003) found that mature dairy cattle had a strong preference for lying down on softer surfaces.

In the current study, BW and pregnancy status of buffaloes did not have any association with stall usage (Table 1). Heavier and lighter buffaloes showed the same stall occupancy. In agreement with our current findings, Tucker et al. (2005) reported that BW did not affect the lying behavior (lying bouts, duration of lying bouts, lying time) of cows in freestalls with different neck rail locations. The neck rail location in our study $(178 \mathrm{~cm})$ was closer to the middle value of neck rail locations $(175 \mathrm{~cm})$ in their study. Similarly, Tucker et al. (2004) did not find any clear association between BW and preference for stalls of different sizes. They also found similar lying behavior (lying bouts, duration of lying bouts, lying time) in cows given a stall width of $116 \mathrm{~cm}$ compared with cows given a stall width of 126 $\mathrm{cm}$; however, a stall width of $106 \mathrm{~cm}$ negatively affected lying behavior. In our study, the stall width was $117 \mathrm{~cm}$. It is possible that after certain limits, spatial constraints were not the main determinant of lying behavior and that, rather, the lying surface was the focus of animals (Tucker et al., 2004). Pregnant and nonpregnant buffaloes had similar freestall occupancy. The maximum imprint width of buffaloes in our study was $107 \mathrm{~cm}$, and stalls were $117 \mathrm{~cm}$ wide. Apparently, stall dimensions did not seem restrictive for buffaloes. In buffaloes, age was the stronger determinant for freestall usage compared with BW and pregnancy status. It implied that older animals were more confident and less fearful in new surroundings than younger animal. However, contrary to current findings, O'Connell et al. (1993)

Table 1. Effect of parity, BW, and pregnancy status on freestall occupancy in Nili Ravi buffaloes $(\mathrm{n}=30)$

\begin{tabular}{llrrr}
\hline Variable $^{1}$ & Category & No. & Days $^{2}($ mean \pm SEM $)$ & $P$-value \\
\hline Parity & Heifers & 4 & $13.5^{\mathrm{a}} \pm 2.1$ & $<0.0001$ \\
& 1 & 4 & $16.8^{\mathrm{a}} \pm 2.1$ & \\
& $\geq 3$ & 10 & $13.2^{\mathrm{a}} \pm 1.5$ & \\
$\mathrm{BW}(\mathrm{kg})$ & 12 & $6.6^{\mathrm{b}} \pm 1.0$ & 0.4351 \\
& 4460 & 5 & $14.2 \pm 3.5$ & \\
& $520-560$ & 10 & $10.4 \pm 3.1$ & \\
Pregnancy status & $>560$ & 11 & $11.1 \pm 3.0$ & \\
& Nonpregnant & 5 & $8.8 \pm 2.6$ & \\
& $1-3$ mo & 5 & $13.3 \pm 3.3$ & \\
& $4-6$ mo & 8 & $10.9 \pm 2.8$ & \\
${ }^{\mathrm{a}, \mathrm{b}}$ Category means with different superscripts are significantly different $(P<0.05)$. & \\
${ }^{1}$ Variables were tested in a univariate analysis. & & & \\
${ }^{2}$ Days taken to start occupying freestalls. & &
\end{tabular}




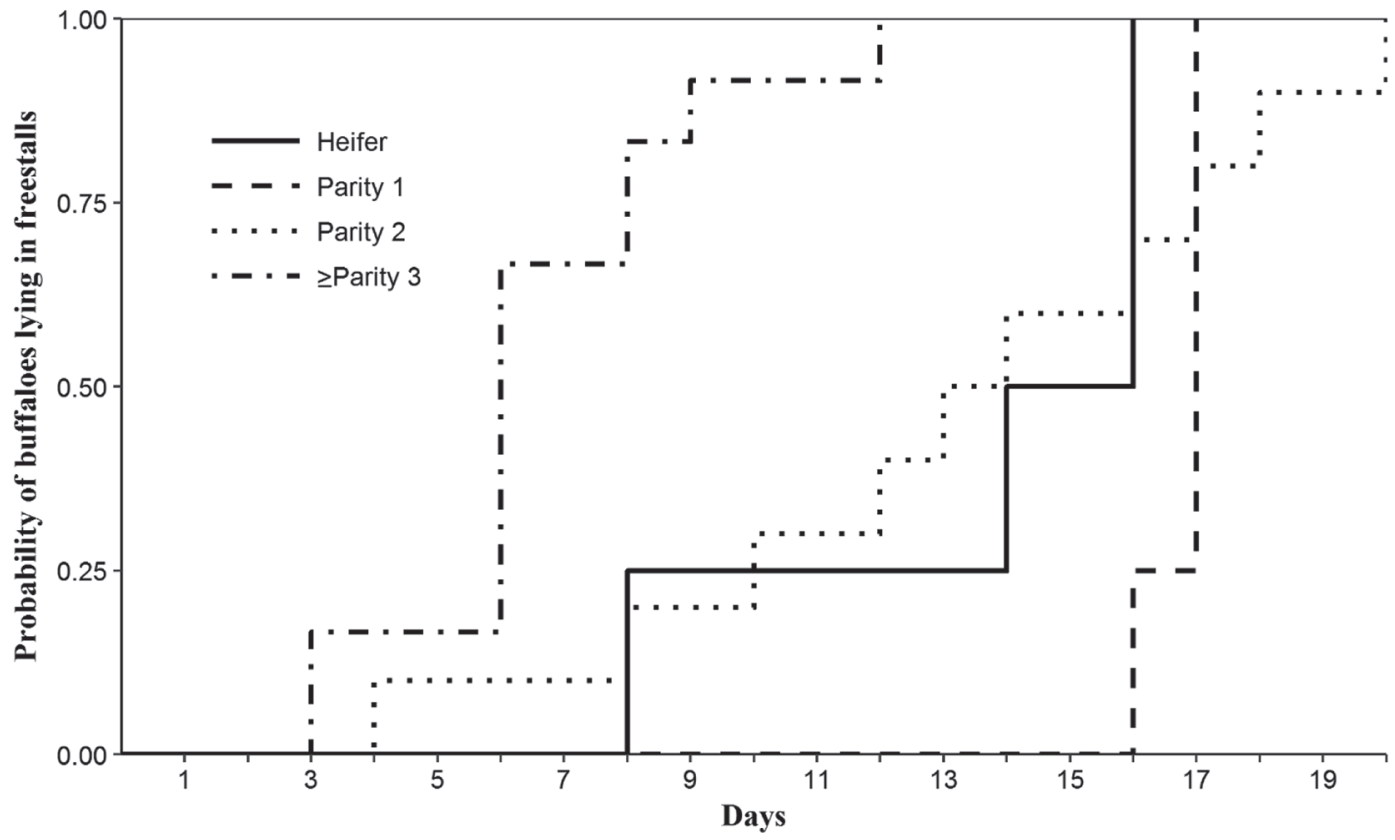

Figure 2. Freestall occupancy events for parity groups in buffaloes. Stall occupancy was considered to be an event when a buffalo occupied a freestall for 3 consecutive days.

found that heifers were easier to train to use freestalls when introduced at weaning versus later in life. Further research is needed to increase our understanding about freestall occupancy behavior of buffaloes.

In conclusion, buffaloes attained maximum freestall occupancy in 3 wk. Buffaloes with parity $\geq 3$ occupied freestalls earlier than younger animals. Body weight and pregnancy status of buffaloes did not affect stall occupancy. Buffaloes showed adjacent stall occupancy, filling opposite stalls first. The current findings would improve the management of these animals in freestall housing and are of critical importance when designing a freestall facility for buffaloes.

\section{ACKNOWLEDGMENTS}

The authors acknowledge the staff of the Dairy Animals Training and Research Center, University of Veterinary and Animal Sciences, Lahore, Ravi Campus, Pakistan.

\section{REFERENCES}

Abade, C. C., J. A. Fregonesi, M. A. G. von Keyserlingk, and D. M. Weary. 2015. Dairy cow preference and usage of an alternative freestall design. J. Dairy Sci. 98:960-965.

Abebe, R., H. Hatiya, M. Abera, B. Megersa, and K. Asmare. 2016. Bovine mastitis: Prevalence, risk factors and isolation of Staphylococcus aureus in dairy herds at Hawassa milk shed, South Ethiopia. BMC Vet. Res. 12:270.
Bernardi, F., J. A. Fregonosi, D. M. Veira, C. Winkler, M. A. G. von Keyserlingk, and D. M. Weary. 2009. The stall-design paradox: Neck rails increase lameness but improve udder and stall hygiene. J. Dairy Sci. 92:3074-3080.

DeVries, T. J., and M. A. G. von Keyserlingk. 2005. Time of feed delivery affects the feeding and lying patterns of dairy cows. J. Dairy Sci. 88:625-631.

Drissler, M., M. Gaworski, C. B. Tucker, and D. M. Weary. 2005. Freestall maintenance: Effects on lying behavior on dairy cattle. J. Dairy Sci. 88:2381-2387.

Færevik, G., K. Jentland, S. Løvik, I. L. Andersen, and K. E. Bøe. 2008. Resting pattern and social behavior of dairy calves housed in pens with different size lying areas. Appl. Anim. Behav. Sci. 114:54-64.

FAOSTAT. 2017. Production: Livestock primary. Food and Agriculture Organization of the United Nations. Accessed Oct. 18, 2017. http://www.fao.org/faostat/en/\#data/QL.

Fregonesi, J. A., and J. D. Leaver. 2002. Preference of lactating dairy cows for straw yard or cubicle housing system for two space allowances. Semin. Cienc. Agrar. 23:45-55.

Fregonesi, J. A., M. A. G. von Keyserlingk, C. B. Tucker, D. M. Veira, and D. M. Weary. 2009a. Neck-rail position in the free stall affects standing behavior and udder and stall cleanliness. J. Dairy Sci. 92:1979-1985.

Fregonesi, J. A., M. A. G. von Keyserlingk, and D. M. Weary. 2009b. Cow preference and usage of free stalls compared with an open pack area. J. Dairy Sci. 92:5497-5502.

Kassambara, A., and M. Kosinski. 2016. Survminer: Drawing survival curves using "ggplot2." R package version 0.2.4. Accessed Mar. 11, 2017. https://CRAN.R-project.org/package=survminer.

Kjæstad, H. P., and H. J. Myren. 2001. Failure to use cubicles and concentrate dispenser by heifers after transfer accommodation to milking herd. Acta Vet. Scand. 42:171-180.

Kjæstad, H. P., and E. Simensen. 2001. Cubicle refusal and rearing accommodation as possible mastitis risk factors in cubicle housed dairy heifers. Acta Vet. Scand. 42:123-130.

Napolitano, F., G. De Rosa, F. Grasso, and A. Bordi. 2004. Influence of space restriction on welfare of weaned buffalo claves (Bubalus bubalis). Livest. Prod. Sci. 86:117-124. 
O'Connell, J. M., P. S. Giller, and W. J. Meaney. 1993. Weanling training and cubical usage as heifers. Appl. Anim. Behav. Sci. $37: 185-195$.

Odyuo, L. T., D. N. Jana, and N. Das. 1995. Maintenance behaviour of Murrah buffalo under an intensive management system. Appl. Anim. Behav. 45:293-299.

R Core Team. 2016. R: A Language and Environment for Statistical Computing. R Foundation for Statistical Computing, Vienna, Austria.

Tucker, C. B., D. M. Weary, and D. Fraser. 2003. Effects of three types of free-stall surfaces on preferences and stall usage by dairy cows. J. Dairy Sci. 86:521-529.

Tucker, C. B., D. M. Weary, and D. Fraser. 2004. Free stall dimensions: Effects on preference and stall usage. J. Dairy Sci. 87:1208-1216.

Tucker, C. B., D. M. Weary, and D. Fraser. 2005. Influence of neck-rail placement on free-stall preference, use, and cleanliness. J. Dairy Sci. 88:2730-2737.
Tucker, C. B., G. Zdanowicz, and D. M. Weary. 2006. Brisket boards reduce freestall use. J. Dairy Sci. 89:2603-2607.

Valde, J. P., D. W. Hird, M. C. Thurmond, and O. Østerås. 1997. Comparison of ketosis, clinical mastitis, somatic cell count, and reproductive performance between free stall and tie stall barns in Norwegian dairy herds with automatic feeding. Acta Vet. Scand. 38:181-192.

von Keyserlingk, M. A. G., G. E. Cunha, J. A. Fregonesi, and D. M. Weary. 2011. Introducing heifers to freestall housing. J. Dairy Sci. 94:1900-1907.

Wickham, H. 2009. ggplot2: Elegant Graphics for Data Analysis. Springer-Verlag, New York, NY. 